\title{
El reconocimiento de los derechos públicos subjetivos y la reforma constitucional en materia de derechos humanos de junio de 2011
}

Recognition of subjective public rights and constitutional reform on human rights June 2011

\author{
Francisco José Murillo Ruiseco \\ Universidad Autónoma de Zacatecas \\ murillo_456@hotmail.com \\ Yanalte Rodríguez Soto \\ Universidad Autónoma de Zacatecas \\ yanalters@hotmail.com \\ Samanta Deciré Bernal Ayala \\ Universidad Autónoma de Zacatecas \\ samanta_bernal@yahoo.com.mx
}

\section{Resumen}

El reconocimiento de los derechos públicos subjetivos constituye uno de los principios fundamentales del Estado moderno. Limitarse a considerar los derechos del hombre frente al Estado como una esfera extrajurídica al modo de Hans Kelsen, o como una capacidad de hacer o no hacer optativa al modo que Eduardo García Máynez, no permite comprender el contenido con que la idea se ha ido presentando históricamente. Los derechos reconocidos al hombre frente al Estado no son puramente libertad en el sentido formalista, sino aptitud de exigir al propio Estado una cierta conducta y no se podrá concebir el concepto en su plenitud sino a condición de que se haga una revisión, siquiera superficial, de su proceso de transformación. 
Palabras clave: Derechos, Públicos, Subjetivos, Estado, Hombre

\begin{abstract}
Recognition of subjective public rights is one of the fundamental principles of the modern state. Merely to consider human rights against the State as an extralegal sphere Hans Kelsen mode, or as an ability to make or not make elective mode Máynez Eduardo Garcia, the content does not explain that the idea has been presented historically. The rights granted to men before the State are not purely formalist freedom in the sense, but ability to require the State itself a certain behavior and you can not conceive the concept in its fullness but on condition that an overhaul, even superficial, of the transformation process.
\end{abstract}

Key words: Rights, Public, Subjective, State, Male

Fecha recepción: Enero $2013 \quad$ Fecha aceptación: Mayo 2013

\title{
Introducción
}

A partir de 1945, tras la finalización de la II Guerra Mundial, se inició un proceso paulatino de internacionalización de los derechos humanos, es decir, un proceso mediante el cual no sólo los Estados sino también la comunidad internacional va a asumir progresivamente competencias en el campo de los derechos humanos.

Como consecuencia de la internacionalización de los derechos humanos han surgido diversos sistemas, tanto universales como regionales, para su protección; sistemas que deben reunir las siguientes características para constituirse en medios efectivos de respeto y protección de los derechos humanos.

La Organización de los Estados Americanos es el organismo regional más antiguo del mundo, cuyo origen se remonta a la Primera Conferencia Internacional Americana, celebrada en Washington, D.C., de octubre de 1889 a abril de 1890. En esta reunión, se acordó crear la Unión 
Internacional de Repúblicas Americanas y se empezó a tejer una red de disposiciones e instituciones que llegaría a conocerse como sistema interamericano, el más antiguo sistema institucional internacional.

La OEA fue creada en 1948 cuando se subscribió, en Bogotá, Colombia, la Carta de la Organización de Estados Americanos que entró en vigencia el 13 de diciembre de 1951. México la ratificó el 23 de noviembre de 1948 y depositó el respectivo instrumento en misma fecha.

El sistema interamericano se inició formalmente con la Declaración Americana de Derechos y Deberes del Hombre, adoptada por la Novena Conferencia Internacional Americana, celebrada en Bogotá, Colombia, en 1948, en la que también se firmó la Carta de la OEA.

La Convención Americana sobre Derechos Humanos (Pacto de San José), se adoptó el 22 de noviembre de 1969 y entró en vigor el 18 julio de 1978, al haber sido depositado el décimo primer instrumento de ratificación por parte de un Estado miembro de la OEA. México lo ratificó el 2 de marzo de 1981 y depositó el respectivo instrumento el día 24 del mismo mes y año.

La Convención Americana significó la consolidación de las labores de supervisión y vigilancia de los derechos humanos que ya poseía la CIDH desde 1965, pero, además, adicionó al sistema una instancia jurisdiccional de interpretación oficial y de decisión definitiva de los casos específicos de violaciones a los derechos establecidos en la propia Convención: la Corte Interamericana de Derechos Humanos.

México aceptó la competencia contenciosa de la Corte Interamericana de Derechos Humanos el 16 de diciembre de 1998, cuando era Presidente Ernesto Zedillo Ponce de León.

El 4 de octubre de 2011, entró en vigor la Décima Época del Semanario Judicial de la Federación y también se publicó en el Diario Oficial de la Federación la llamada sentencia Rosendo Radilla, lo que significa la novación del sistema de impartición de justicia para el país, en el cual, todos los jueces mexicanos, en acatamiento a las obligaciones que se comprometen en el sistema interamericano, deberán hacer valer, los derechos humanos de todas las personas en el ámbito de sus respectivas competencias. 
La creación de la Décima Época es más que un acto administrativo, simboliza el inicio de un cambio en la perspectiva de impartir justicia, cuyo resultado, quizá hoy, no podríamos medir en su correcta dimensión.

El 25 de agosto de 1974, detuvieron ilegalmente en un retén militar al señor Rosendo Radilla Pacheco, quien fue visto por última vez en el Ex Cuartel Militar de Atoyac de Álvarez, Guerrero. Rosendo Radilla fue un destacado y querido líder social del municipio de Atoyac de Álvarez, Guerrero, quien trabajó por la salud y educación de su pueblo y quien fungió como presidente Municipal.

La detención y posterior desaparición forzada del señor Radilla Pacheco fue denunciada públicamente por la familia en el momento de sucedidos los hechos y posteriormente fue denunciada legalmente ante las instancias de procuración de justicia nacionales; fue parte de la investigación realizada por la Comisión Nacional de Derechos Humanos la cual concluyó en un Informe Especial publicado en el año 2001 conjuntamente con la recomendación 26/2001 e igualmente fue una de las averiguaciones previas investigadas por la Fiscalía Especial creada en la transición democrática con el fin -no alcanzado- de aclarar los crímenes del pasado, dicha fiscalía fue cerrada de forma inesperada el 30 de noviembre de 2006.

El 15 de marzo de 2008 la Comisión Interamericana de Derechos Humanos sometió a la Corte una demanda en contra de los Estados Unidos Mexicanos, la cual se originó en la denuncia presentada el 15 de noviembre de 2001 por la Comisión Mexicana de Defensa y Promoción de los Derechos Humanos y por la Asociación de Familiares de DetenidosDesaparecidos y Víctimas de Violaciones a los Derechos Humanos en México. El 23 de noviembre de 2009 la Corte Interamericana de Derechos Humanos dictó sentencia.

El 10 de junio de 2011, se publicaron importantes reformas a la Constitución Política de los Estados Unidos Mexicanos. En ella, se evidencia el reconocimiento de la progresividad de los derechos humanos, mediante la expresión clara del principio pro persona como rector de la interpretación y aplicación de las normas jurídicas, en aquellas que favorezcan y brinden mayor protección a las personas. 


\section{El reconocimiento de los derechos del individuo frente al Estado}

El reconocimiento de los derechos del individuo frente al Estado, logra su consagración en la "Declaración de Derechos del Hombre y del Ciudadano" (Jellinek, 2000, pág. 167) hecha en Francia el 26 de agosto de 1789, compuesta de diecisiete artículos, el segundo de los cuales definía, "El fin de toda asociación política es la conservación de los derechos naturales e imprescriptibles del hombre. Estos derechos son la libertad, la propiedad, la seguridad y la resistencia a la opresión".

A esa declaración se le considera inspirada en documentos ingleses y americanos; por tanto, haremos una revisión de tales antecedentes y luego volveremos a ocuparnos de la declaración francesa.

La historia política inglesa conoce de guerras civiles, de revoluciones y de otros actos de violencia. Parece raro que se pueda hablar de la constitución británica como de una constitución tradicional, no revolucionaria. Y sin embargo, esta afirmación es cierta en lo fundamental, si por revolución entendemos el establecimiento de un orden nuevo mediante el empleo de la violencia. Pues, en efecto, mientras que las revoluciones europeas y americanas nacidas en la época del racionalismo, buscaban su legitimidad en principios racionales, y su justificación en lo irracional del orden existente, en cambio, las revoluciones inglesas, por la época histórica en que aparecen y también por las peculiaridades históricas de dicho pueblo, se legitiman y justifican al modo tradicional, es decir, por su intención de restaurar un antiguo orden quebrantado por el monarca y sus colaboradores. Más que abolir viejos textos e instituciones, lo que se vino haciendo fue darles un nuevo sentido, de aquí que en medio de los cambios sea posible encontrar una línea de permanencia y continuidad.

En el año de 1215 los estamentos privilegiados (1) forman ante el rey Juan Sin Tierra(2) un movimiento de resistencia cuya consecuencia es la "Magna Charta Libertatum". En esta carta no se pretende crear nada nuevo, sino restablecer antiguas costumbres y para tal efecto expresa una serie de derechos subjetivos de índole heterogénea: desde las normas de derecho hereditario o matrimonial; límites a la prerrogativa del monarca en materia de impuestos y, en 
general, a cualquier medida del monarca que afectara a los hombres libres que poseían la tierra en propiedad.

En el año de 1627 los lores formularon una serie de demandas ante el rey Carlos I, que se conoce con el nombre de "Petition of Rights" (Jellinek, 2000, pág. 107). El documento se presenta como una reacción ante abusos que fueron enumerados. En 1679 se formuló el “Habeas Corpus" (Jellinek, 2000, pág. 107).

En 1688, con la huída del rey de Escocia Jacobo II a Francia, el Parlamento declara vacante el trono y se llama a Guillermo de Orange-Nassau el Taciturno quien recibe el cetro mediante juramento de una declaración escrita que se conoce con el nombre de "Bill of Rigths" de 1689 (Jellinek, 2000, pág. 107).

Las declaraciones contenidas en los documentos aludidos, revelan un sentido práctico, no obedecen a construcciones especulativas, no tiene ninguna nota propiamente doctrinaria, sino que se ofrecen como resultado de la experiencia que los señores ingleses habían ido acumulando a través del desarrollo histórico de su comunidad.

Además como característica de especial relieve se ha de apuntar que los derechos cuyo reconocimiento se exigió en dichos documentos, no eran entendidos como derechos de la persona humana, como derechos de todos los hombres, sino simplemente como prerrogativa del súbdito inglés; inclusive los liberi homines de que se hablaba en la Magna Carta, no eran todos los hombres ingleses, sino los que formaban la nobleza.

El estadista, filósofo y político británico nacido en Irlanda Edmund Burke ha dicho que se trató de afirmar libertades que se estimaban legadas a los ingleses por sus antecesores y que ellos habrían de trasmitir a su posteridad como propiedad perteneciente al pueblo, así "las convenciones de la constitución, los derechos y deberes tradicionales de los ingleses, la presencia viva de una rica cultura nacional trasmitida de generación en generación no eran abstracciones sino existencias reales, desarrolladas con el calor del patriotismo ardiente y el ardor del sentimiento moral. [...] la vida colectiva de Inglaterra llega a ser una realidad consciente" (Sabine, 2006, pág. 453). El jurista inglés, profesor de la universidad de Oxford, Sir William Blackstone a su vez indicó que son aquellos documentos meras declaraciones de derechos y 
libertades innatas a los ingleses "son derechos absolutos de todo inglés" (Jellinek, 2000, pág. 112). En el ambiente ideológico de las trece colonias inglesas que se formaron en Norteamérica, se mantuvo la creencia en ciertos derechos pertenecientes a la calidad del inglés, que más tarde pasaron a ser considerados como inherentes a la personalidad humana.

Se ha subrayado la circunstancia de que el reconocimiento de esos derechos está inspirado no solamente en los antecedentes ingleses, sino en el flujo del derecho natural y en general en la filosofía política que alimentaron Rousseau, el filósofo y médico inglés John Locke, el escritor y jurista francés Charles-Louis de Montesquieu y el escritor y filósofo francés François Marie Atouet Voltaire; y esto explica el que en ello se descubra como rasgo fundamental, su generalidad; ya no se trata de derechos de estamentos privilegiados, ni siquiera de derechos de los súbditos todos de un determinado Estado, como ocurría en los documentos ingleses, sino de los derechos de la persona en general, de todos los hombres.

Jellinek cita un comentario del político e historiador estadounidense George Bancroft, en el sentido de que mientras "La petición de Derechos inglesa del año 1688 era histórica y retrospectiva; la declaración de Virginia viene directamente del corazón de la naturaleza, y proclama los principios de gobierno para todos los pueblos de todos los tiempos futuros" (Jellinek, 2000, pág. 108). El autor germano precisa que para las declaraciones americanas el individuo no debe al Estado, sino a su propia naturaleza de sujeto de derechos, los derechos subjetivos inalienables e inviolables de que disfruta; en cambio, en las leyes inglesas no se reconoció un derecho natural eterno, sino solamente un derecho que viene de los antepasados, "los derechos antiguos, indiscutibles, del pueblo inglés" (Jellinek, 2000, pág. 109).

También destaca Jellinek este punto, "Las leyes inglesas están muy lejos de querer reconocer los derechos generales del hombre; no tienen ni la fuerza ni la intención de limitar los factores legislativos, ni tampoco tratan de formular principios para una legislación del porvenir. Según el Derecho inglés, el Parlamento es omnipotente: todas las leyes por él aceptadas o elaboradas tienen igual valor. Las declaraciones americanas, por el contrario, contienen reglas que están por encima del legislador ordinario" (Jellinek, 2000, pág. 108). 
Hecha la anterior reseña, volvamos a la declaración de derechos francesa de 26 de agosto de 1789 (Jellinek, 2000, pág. 96). Su contenido, en síntesis, es el siguiente: los hombres nacen libres e iguales en derecho; los derechos naturales e imprescindibles del hombre son, la libertad, la propiedad, la seguridad y la resistencia a la opresión; el fin del Estado es la conservación de esos derechos; el principio de toda soberanía reside esencialmente en la Nación; la libertad consiste en poder hacer todo lo que no perjudique a otro; la ley sólo puede prohibir las acciones nocivas a la sociedad; la ley expresa la voluntad general y todos los ciudadanos tienen el derecho de concurrir a su formación, ella ha de ser la misma para todos; los ciudadanos son admisibles a toda las dignidades, cargos y empleos públicos, según su capacidad, sin más distinción que la de sus virtudes y su talento; nadie puede ser acusado o detenido sino en los casos determinados por la ley y con las formalidades en ella prescritas; los que libren órdenes arbitrarias han de ser castigados; la ley ha de fijar las penas estrictamente necesarias y nadie podrá ser castigado sino conforme a la ley establecida con anterioridad al delito y legalmente aplicada; se presume la inocencia de todo hombre mientras no sea declarado culpable, por tanto, todo rigor innecesario para el aseguramiento de su persona debe ser severamente reprimido; nadie podrá ser molestado por sus opiniones, aun las religiosas, mientras la manifestación de ellas no perturbe el orden público; todo ciudadano puede hablar, escribir e imprimir libremente su pensamiento sujeto a responder de los abusos en que incurra; la fuerza pública se instituye para ventaja de todos y no para la particular utilidad de aquellos a quienes está confiada; la contribución para los gastos públicos debe quedar repartida igualmente entre los ciudadanos en razón de sus capacidades; todos los ciudadanos tienen derecho de constatar la necesidad de la contribución, así como el de consentirla libremente, investigar su empleo, determinar la calidad, la cuota, el pago y su duración; la sociedad tiene derecho a pedir cuentas de su administración a todo funcionario público; la sociedad que no tiene asegurada la garantía de sus derechos, ni tiene determinada la separación de sus poderes, carece de Constitución; nadie puede ser privado de sus propiedades sino por exigencia de una necesidad pública comprobada y bajo la condición de una previa y justa indemnización. 
Si bien la originalidad de las ideas contenidas en aquel documento francés ha sido discutida con bastante fundamento, tal hecho no quita a ese documento su significación histórica, proyectada desde el ángulo de la tremenda fuerza expansiva que les comunicó. Como sucedió con algunas declaraciones americanas, ella fue incorporada a la Constitución de 3 de septiembre de 1791 (Jellinek, 2000, pág. 82) formándose con ello definitivamente el modo clásico para las cartas constitucionales del futuro, una primera parte dogmática, donde se catalogan los derechos de la persona y una segunda parte orgánica, que atiende a la estructura, atribuciones y relaciones de los órganos del Estado.

Al lado del concepto de derechos públicos individuales, ha sido colocado el concepto de derechos públicos sociales. Para tener idea sobre los fundamentos de tal distinción, se pueden plantear aquí los siguientes párrafos.

La filosofía humanista y cosmopolita de las revoluciones francesa y americana, aun teniendo un indudable fundamento de verdad, era insuficiente para resolver los problemas de la vida económica y social; se dejaba en pie el grave desacuerdo entre la igualdad jurídica y la desigualdad efectiva del individuo, constreñido por el hecho de haber nacido pobre, a aceptar una especie de esclavitud poco diferente de la antigua; lo que había llevado a pedir la aplicación de los principios de libertad, igualdad y fraternidad, también a los campos económico y social. Este movimiento ideológico de lucha por la libertad social, como corolario de la libertad jurídicopolítica, ganada en la revolución francesa y americana, se inicia en su primera etapa, en la revolución de 1848 en Europa y con la adopción de medidas sociales por la Constitución francesa de 1848.

Por lo tanto, mientras la realización de los valores contenido de los derechos públicos individuales tendrá lugar por los individuos, siempre que el Estado no lo impida, los valores que dan contenido a los derechos sociales exigen, ante la insuficiencia del esfuerzo personal, la actividad del Estado para su satisfacción. Es decir, los derechos públicos individuales tienen como condición de logro una actitud de abstención del Estado; que éste no se inmiscuya obstruyendo la esfera de libertad de los individuos; en cambio los derechos sociales reclaman la intervención del Estado, reduciendo inclusive el círculo de libertad individual. 
Los derechos sociales corresponden al ser humano, valorando el aspecto colectivo de su naturaleza, y se inspiran en el propósito de contener los excesos del individualismo, para realizar el mejoramiento de las clases económicamente débiles; originariamente los derechos sociales aparecieron como referidos de manera particular a la clase trabajadora. Pero su esencia y contenido desborda el concepto de trabajador para llegar a abarcar a todos los económicamente débiles, es decir, a todo aquel que requiere el auxilio o la ayuda de la comunidad.

Nunca se insistirá demasiado en que el reconocimiento de una u otra de las categorías de derechos que antes hemos mencionado, no es privativa de una escuela de pensamiento en detrimento de las demás; que así como no es menester ser rousseauniano para reconocer los derechos individuales, tampoco hace falta ser marxista para reconocer los derechos sociales; que las adquisiciones de la inteligencia común, bajo la acción de las diversas corrientes que en ella se cruzan, sobrepasan enormemente las disputas de escuela.

Podemos decir que una y otra especie de derechos es traducción de ese afán de libertad por el que el hombre se apremia a sí mismo en razón de la exigencia de su humana esencia.

Por tal razón nos parece inexacto pretender llamar a los derechos sociales "nuevos derechos", como lo han hecho algunos autores contemporáneos, que tildan a los individuales de ser "antiguos", si es que no de "anticuados". Para nosotros, esa forma de distinguir debe ser tomada con reservas, aceptándola sólo en cuanto alude al simple desarrollo de los conceptos, pues de otro modo, en cuanto se pretenda que se trata de realidades nacidas unas después de otras, se incurrirá en falsos entendimientos.

$\mathrm{Ni}$ la declaración francesa que antes citamos, ni cualquiera otro documento que la historia nos presente, pueden ser tomados como origen de unos $u$ otros derechos. Esas declaraciones, como los documentos constitucionales que en cada Estado se ocupan de consignarlos, no son más que las piezas en que públicamente se les ha reconocido transportándolos hasta el derecho positivo; porque ellos nacieron con el hombre como individuo y con el hombre como ente social, y sólo a fuerza de abstracción se puede imaginar al ser humano fuera de sociedad, en el Estado original que imaginaba Rousseau. 
Además, es grave error entender que entre los derechos individuales y los sociales existe planteada una situación de antagonismo, de oposición; quien así piense olvidará que el hombre social no puede ser separado del hombre individuo, sino, como antes se dijo, en plan meramente de abstracción, ya que la entidad a que ambos conceptos se refieren es justamente la persona humana.

De tal modo, la expresión derechos del hombre, o por mejor decir, derechos humanos, supera aquella dualidad comprendiendo ambas nociones, pues háblese de derechos individuales o háblese de derechos sociales, queda imprescindible la referencia a la esencia humana. 


\section{Conclusión}

El reconocimiento de los derechos públicos subjetivos constituye uno de los principios fundamentales del Estado moderno. Limitarse a considerar los derechos del hombre frente al Estado como una esfera extrajurídica al modo de Hans Kelsen, o como una capacidad de hacer o no hacer optativa al modo que Eduardo García Máynez, no permite comprender el contenido con que la idea se ha ido presentando históricamente. Los derechos reconocidos al hombre frente al Estado no son puramente libertad en el sentido formalista, sino aptitud de exigir al propio Estado una cierta conducta y no se podrá concebir el concepto en su plenitud sino a condición de que se haga una revisión, siquiera superficial, de su proceso de transformación.

El 4 de octubre de 2011, entró en vigor la Décima Época del Semanario Judicial de la Federación y también se publicó en el Diario Oficial de la Federación la llamada Sentencia Rosendo Radilla, lo que significa la novación del sistema de impartición de justicia para el país, en el cual, todos los jueces mexicanos, en acatamiento a las obligaciones que se comprometen en el sistema interamericano, deberán hacer valer, los derechos humanos de todas las personas en el ámbito de sus respectivas competencias.

En relación con las prácticas judiciales, la Corte Interamericana de Derechos Humanos ha establecido en su jurisprudencia que es consciente de que los jueces y tribunales internos están sujetos al imperio de la ley y, por ello, están obligados a aplicar las disposiciones vigentes en el ordenamiento jurídico. Pero cuando un Estado ha ratificado un tratado internacional como la Convención Americana sobre Derechos Humanos, sus jueces, como parte del aparato del Estado, también están sometidos a ella, lo que les obliga a velar porque los efectos de las disposiciones de la Convención no se vean mermados por la aplicación de leyes contrarias a su objeto y fin, que desde un inicio carecen de efectos jurídicos. En otras palabras, el Poder Judicial de la Federación debe ejercer un "control de convencionalidad" ex officio entre las normas internas y la Convención Americana, evidentemente en el marco de sus respectivas competencias y de las regulaciones procesales correspondientes. En esta tarea, el Poder Judicial de la Federación debe tener en cuenta no solamente el tratado, sino también la interpretación 
que del mismo ha hecho la Corte Interamericana, intérprete última de la Convención Americana.

Notas aclaratorias

(1) Los estamentos privilegiados son grupos sociales cerrados, en los que no se deja entrar a nadie que no acredite su nobleza heredada (honor) u otorgada por el rey (mérito). Hasta el siglo XVIII la nobleza, el alto clero y la Corona comparten el poder dentro de una estructura social estable.

(2) Rey de Inglaterra, de 1199 a 1216. A la muerte de su hermano, Ricardo Corazón de León, asesinó a su sobrino Arturo de Ruán en 1203. Derrotado por los barones y prelados ingleses, fue obligado a conceder la famosa Carta Magna de las libertades inglesas.

\section{Bibliografía}

Jellinek, Georg. (2000). La Declaración de los Derechos del Hombre y del Ciudadano. México: Instituto de Investigaciones Jurídicas de la Universidad Nacional Autónoma de México.

Sabine, George H. (2006). Historia de la teoría política. México: Fondo de Cultura Económica. 